\title{
Synthesis of poly(ethyl methacrylate-co-methyl methacrylate) obtained via ATRP using ruthenium benzylidene complexes
}

\author{
Maria Beatriz Alves Afonso ${ }^{1}$, Lucas Gomes Gonçalves ${ }^{1}$, Talita Teixeira Silva², José Luiz Silva Sá ${ }^{2}$ \\ Nouga Cardoso Batista ${ }^{2}$, Beatriz Eleutério Goi ${ }^{1}$ and Valdemiro Pereira Carvalho Júnior ${ }^{1 *}$ \\ ${ }^{1}$ Faculdade de Ciências e Tecnologia - FCT, Universidade Estadual Paulista - UNESP, \\ Presidente Prudente, SP, Brasil \\ ${ }^{2}$ Núcleo Interinstitucional de Estudo e Geração de Novas Tecnologias - GERATEC, \\ Departamento de Química - DQ, Universidade Estadual do Piauí - UESPI, Teresina, PI, Brasil \\ *valdemiro@fct.unesp.br
}

\begin{abstract}
Atom-Transfer Radical Copolymerization (ATRP) of methyl methacrylate (MMA) and ethyl methacrylate (EMA) under different reaction conditions was conducted using Grubbs $1^{\text {st }}(\mathbf{1})$ and $2^{\text {nd }}(\mathbf{2})$ generation catalysts. Initially, the study focused on the reactivity of the catalysts in ATRP of EMA individually, then the syntheses of poly(MMA-co-EMA) were also conducted in different mixtures of monomers ([MMA]/[EMA] = 100/200 and [MMA]/[EMA] $=200 / 100)$. Conversion and semilogarithmic kinetic plots as a function of time were related to the different catalysts and reaction conditions. The values of $\mathrm{M}_{\mathrm{n}}$ and PDI also changed when different catalysts were used in the presence of $\mathrm{Al}(\mathrm{O} i \mathrm{Pr})_{3}$, and more controlled polymerizations were achieved using 1. In the syntheses of poly(MMA)-co-(EMA), conversion of $60 \%$ was reached for both catalysts at different [MMA]/[EMA] ratios for $16 \mathrm{~h}$; however, for shorter time, $4 \mathrm{~h}$, better conversion values were obtained using 1 as catalyst for both [MMA]/[EMA] =100/200 or 200/100.
\end{abstract}

Keywords: methyl methacrylate, ethyl methacrylate, copolymer, ATRP, Grubbs catalysts.

\section{Introduction}

Atom-transfer radical polymerization (ATRP) was pioneered by the research groups of Kato et al..$^{[1]}$ and Wang and Matyjaszewski ${ }^{[2,3]}$. ATRP is based on atom transfer radical addition (ATRA) - a modified Kharasch addition in which a transition metal complex catalyzes the addition of an alkyl halide across a carbon-carbon double bond. A radical species is generated by the transfer of a halogen atom from the alkyl halide to the transition metal complex. Radicals are generated in ATRP through a reversible redox process, catalyzed by a metal-ligand complex which undergoes a one-electron oxidation and abstracts a halogen atom from a dormant species (Scheme 1).

ATRP has proven versatile for the synthesis of copolymers with desired molecular weight in various forms and compositions because of the wide range of vinyl monomers susceptible to this polymerization ${ }^{[1-3]}$. Moreover, ATRP is attractive due to its simple experimental setup and commercial availability of initiators and catalyst components, while maintaining exquisite control and versatility ${ }^{[1-12]}$.

ATRP is a catalyst-based process in which the growing radicals can be reversibly activated or deactivated via dynamic equilibrium using a transition metal complex with exchange of halide species between the chain end and the metal complex ${ }^{[13]}$. The metal should present two readily accessible oxidation states separated by one electron, reasonable affinity towards the halogen, expandable coordination sphere upon oxidation to accept the halogen atom, and be relatively strongly complexed by the ligand ${ }^{[13]}$. Although a variety of metal complexes has been used as ATRP catalysts ${ }^{[14-17]}$, ruthenium has probably received the most attention because of its wide versatility in the coupling of different reactions via tandem process. In particular, Grubbs $1^{\text {st }}(\mathbf{1})$ and $2^{\text {nd }}(\mathbf{2})$ generation metathesis catalysts have shown excellent application in promoting two reactions with such markedly different mechanisms via various tandem reactions in which olefin metathesis and atom transfer radical reactions occur in one pot ${ }^{[18]}$. As complexes $\mathbf{1}$ and $\mathbf{2}$ were known to be active for ROMP and ATRP reactions ${ }^{[19-21]}$, we expanded our investigations towards exploration of the activity of both catalysts in the copolymerization of methacrylate monomers.

Methacrylate copolymers are a class of functional polymer materials and have been widely used in many fields because of their resistance to enzymatic attack, biocompatibility, and high optical qualities. Particularly, copolymerization of MMA and EMA is rare, with few cases reported in the literature, in which the researchers used both monomers to produce copolymers via conventional polymerization. Kitayama et al. ${ }^{[22,23]}$ and Zune et al. ${ }^{[24]}$ investigated the synthesis of MMA/EMA copolymers by anionic polymerization. Dzulkurnain et al. ${ }^{[25]}$ reported the synthesis of random copolymers with three different ratios of 


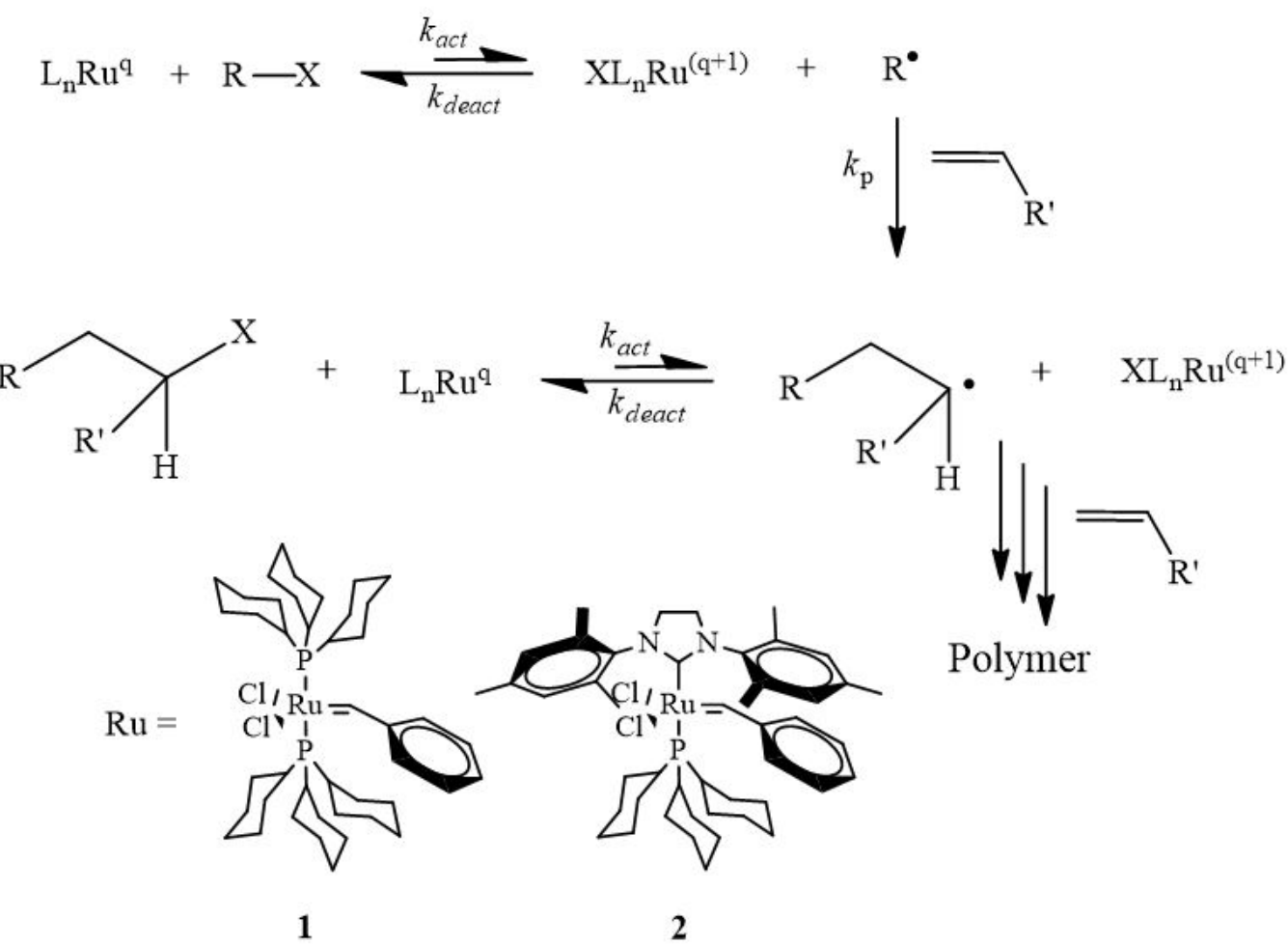

Scheme 1. Illustration of ATRP reaction; the termination step is not shown for clarity.

EMA and MMA using the free-radical bulk polymerization method. Copolymerization of MMA with EMA conducted in a continuous stirred-tank reactor was reported by Shin and Seul ${ }^{[26]}$. Liu et al. ${ }^{[27]}$ performed bulk copolymerization of MMA with EMA via free radical polymerization using azo initiator (AIBN) and studied the copolymer thermal properties. Free radical dispersion copolymerization of methyl and ethyl methacrylate in supercritical carbon dioxide was reported by Giles et al. ${ }^{[28]}$.

The present study aimed to optimize the reaction conditions for the controlled copolymerization of MMA and EMA by ATRP using ruthenium-based metathesis catalysts. The homopolymerization of EMA and its copolymerization with MMA via ATRP using Grubbs catalysts in different reaction conditions were investigated. At first, the aim of this work was to evaluate the reactivity of $\mathbf{1}$ and $\mathbf{2}$ in ATRP of EMA reaction individually, then poly(MMA-co-EMA) were also obtained in different mixtures of monomers. The complexes $\mathbf{1}$ and $\mathbf{2}$ were able to mediate these polymerizations with acceptable rate and level of control. Random copolymerization of the previously mentioned monomers was conducted to establish the most favorable conditions to obtain polymers with desired molecular weights and compositions.

\section{Materials and Methods}

\subsection{General details}

All reagents were purchased from Aldrich Chemical Co. All reactions and manipulations were conducted under a nitrogen atmosphere using standard Schlenk techniques.
Toluene was dried overnight over calcium chloride, filtered and distilled from sodium benzophenone ketyl and degassed by three vacuum-nitrogen cycles under nitrogen before use. The monomers methyl methacrylate (MMA) and ethyl methacrylate (EMA) were washed with $5 \% \mathrm{NaOH}$ solution, dried over anhydrous $\mathrm{MgSO}_{4}$, vacuum distilled from $\mathrm{CaH}_{2}$ and stored at $-18^{\circ} \mathrm{C}$ before use. Grubbs $1^{\text {st }}$ and $2^{\text {nd }}$ generation catalysts, anisole, 2,2,6,6-tetramethyl-1-piperidinyloxy (TEMPO), aluminium isopropoxide $\left(\mathrm{Al}(\mathrm{O} i \mathrm{Pr})_{3}\right)$ and ethyl 2-bromoisobutyrate $(\mathrm{EB} i \mathrm{~B})$ were used as acquired.

\subsection{Homopolymers synthesis}

A ruthenium complex $(23.5 \mu \mathrm{mol})$ was placed in a Schlenk tube containing a magnet bar and capped with a rubber septum. Air was expelled by three vacuum-nitrogen cycles before the monomer (EMA; $4.71 \mathrm{mmol}$ ) and the initiator solution ( $\mathrm{EB} i \mathrm{~B} ; 48.2 \mu \mathrm{mol})$ were added. All liquids were handled with dried syringes under nitrogen. The tube was capped under $\mathrm{N}_{2}$ atmosphere using Schlenk techniques, then the reaction mixture was magnetically stirred and heated in a thermostated oil bath at $85^{\circ} \mathrm{C}$. Aliquots $(20 \mu \mathrm{L})$ were removed at appropriate intervals.

\subsection{Copolymer synthesis}

The same procedure was used for the copolymerizations, except for the fact that two monomers were added into a Schlenk tube. In a typical ATRP experiment for a $[\mathrm{MMA}]_{200}[\mathrm{EMA}]_{100}$ solution, a mass of MMA corresponding to $4.71 \mathrm{mmol}$ was added into a reaction tube, resulting in a $[$ Monomer $] /[\mathrm{Ru}]=200$ (means, $\left.[\mathrm{MMA}]_{200}\right)$. After that, 
a mass of EMA for a [Monomer $] /[\mathrm{Ru}]=100$ was added $\left([\mathrm{EMA}]_{100}=2.35 \mathrm{mmol}\right)$. The tube was capped under $\mathrm{N}_{2}$ atmosphere using Schlenk techniques, the reaction mixture was then magnetically stirred and heated in a thermostated oil bath at $85^{\circ} \mathrm{C}$. Aliquots $(20 \mu \mathrm{L})$ were removed at appropriate intervals.

\subsection{Analyses}

Conversion was determined from the concentration of residual monomer measured by gas chromatography (GC) using a Shimadzu GC-2010 gas chromatograph equipped with flame ionization detector and a $30 \mathrm{~m}(0.53 \mathrm{~mm}$ I.D., $0.5 \mu \mathrm{m}$ film thickness) SPB-1 Supelco fused silica capillary column. Anisole was added to polymerization and used as an internal standard. Analysis conditions: injector and detector temperature, $250{ }^{\circ} \mathrm{C}$; temperature program, $40{ }^{\circ} \mathrm{C}(4 \mathrm{~min})$, $20{ }^{\circ} \mathrm{C} \mathrm{min}$ mintil $^{-1} 200{ }^{\circ} \mathrm{C}, 200{ }^{\circ} \mathrm{C}$ (2 min). The molecular weights and the molecular weight distribution of the polymers were determined by gel permeation chromatography using a Shimadzu Prominence LC system equipped with a LC-20AD pump, a DGU-20A5 degasser, a CBM-20A communication module, a CTO-20A oven at $40^{\circ} \mathrm{C}$, and a RID-10A detector equipped with two Shimadzu columns (GPC-805: $30 \mathrm{~cm}$, $\varnothing=8.0 \mathrm{~mm})$. The retention time was calibrated with standard monodispersed polystyrene using HPLC-grade THF as an eluent at $40{ }^{\circ} \mathrm{C}$ with a flow rate of $1.0 \mathrm{~mL} \mathrm{~min}^{-1}$. Theoretical molecular weights were calculated without considering the end groups according to the following equation: $\mathrm{M}_{\mathrm{n}, \mathrm{th}}=\left([\text { Monomer }]_{0} /[\text { Initiator }]_{0}\right) \times$ Conversion $\times \mathrm{M}_{\text {Wmonomer }}$. The ${ }^{1} \mathrm{H}$ NMR spectra were obtained in $\mathrm{CDCl}_{3}$ at $298 \mathrm{~K}$ on a Bruker DRX-400 spectrometer operating at $400.13 \mathrm{MHz}$. The obtained chemical shifts were reported in ppm relative to TMS. DSC experiments were performed using a SDT Q600 (V20.9 Build 20). The samples $(10.0 \pm 0.1 \mathrm{mg})$ in an aluminum open sample holder were heated at $10{ }^{\circ} \mathrm{C} \mathrm{min}{ }^{-1}$ from 20 to $180{ }^{\circ} \mathrm{C}$ in $\mathrm{N}_{2}$ atmosphere $\left(20 \mathrm{~cm}^{3} / \mathrm{min}\right)$.

\section{Results and Discussion}

ATRP of EMA was conducted in the presence of $\mathrm{Al}(\mathrm{O} i \mathrm{Pr})_{3}$ with initial molar ratio of $[$ Monomer] $/[\mathrm{EB} i \mathrm{~B}] /[\mathrm{Ru}]=200 / 2 / 1$ using $\mathbf{1}$ or $\mathbf{2}$ as catalysts. With 1, poly(EMA) was obtained with $8 \%$ of conversion in $4 \mathrm{~h}$, increasing to $65 \%$ when reaction time is increased to $16 \mathrm{~h}$; whereas with 2 as catalyst under similar conditions, $6 \%$ of conversion was observed in $4 \mathrm{~h}$, increasing to $44 \%$ after $16 \mathrm{~h}$ of reaction (Figure 1 ). Semilogarithmic plots of the reaction time for ATRP of EMA showed a linear profile, with $k_{\text {obs }}=2.14 \times 10^{-5} \mathrm{~s}^{-1}$ for $\mathbf{1}$ and $k_{\mathrm{obs}}=1.21 \times 10^{-5} \mathrm{~s}^{-1}$ for $\mathbf{2}$, indicating that the radical concentration was constant throughout the polymerization (Figure 2).

$M_{n}$ values increased linearly with increased conversion and were followed by a decrease in the PDI values (Figure 3 ). The results are consistent with a certain degree of control for the polymerizations (low dispersity; $M_{n}$ increasing with conversion for both catalyts). However, when comparing the polymerization control of EMA mediated by $\mathbf{1}$ and $\mathbf{2}$, the molecular weights of polyEMA obtained with $\mathbf{1}$ are in better agreement with the theoretical values for a controlled process.

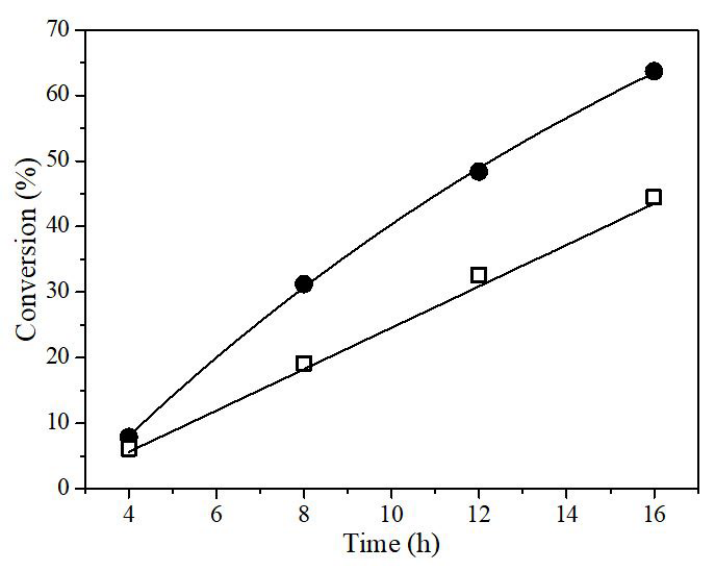

Figure 1. Dependence of conversion on the reaction time for ATRP of EMA in the presence of $\mathrm{Al}(\mathrm{O} i \mathrm{Pr})_{3}$ using 1 or 2 in toluene at $85{ }^{\circ} \mathrm{C} ;(\bullet)[\mathrm{EMA}] /[\mathrm{EB} i \mathrm{~B}] /[\mathrm{Al}] /[1]=200 / 2 / 4 / 1$; () $[\mathrm{EMA}] /[\mathrm{EB} i \mathrm{~B}] /[\mathrm{Al}] /[2]=200 / 2 / 4 / 1$.

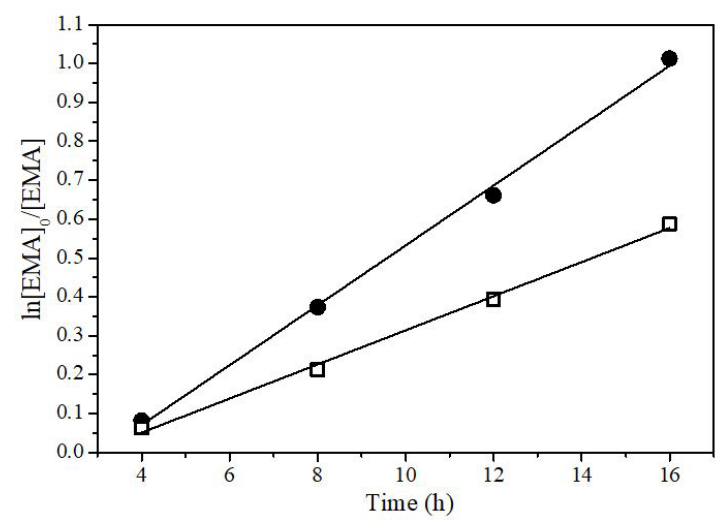

Figure 2. Semilogarithmic plots on the reaction time for ATRP of EMA in the presence of $\mathrm{Al}(\mathrm{OiPr}) 3$ using 1 or 2 in toluene at $85{ }^{\circ} \mathrm{C} ;(\bullet)[\mathrm{EMA}] /[\mathrm{EBiB}] /[\mathrm{Al}] /[1]=200 / 2 / 4 / 1$; (口) $[\mathrm{EMA}] /[\mathrm{EBiB}] /[\mathrm{Al}] /[2]=200 / 2 / 4 / 1$.

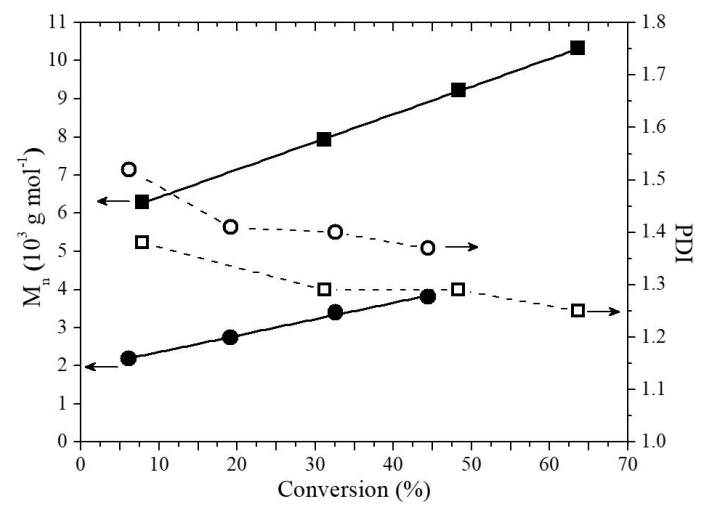

Figure 3. Dependence of $\mathrm{M}_{\mathrm{n}}$ (solid) and PDI (hollow) values on conversion for ATRP of EMA in the presence of $\mathrm{Al}(\mathrm{O} i \mathrm{Pr})_{3}$ using $\mathbf{1}$ or $\mathbf{2}$ in toluene at $85^{\circ} \mathrm{C} ;(\bullet)[\mathrm{EMA}] /[\mathrm{EB} i \mathrm{~B}] /[\mathrm{Al}] /[\mathbf{1}]=200 / 2 / 4 / 1$; (a) $[\mathrm{EMA}] /[\mathrm{EBiB}] /[\mathrm{Al}] /[2] /=200 / 2 / 4 / 1$. 
Copolymerization conversion of MMA and EMA was sensitive to [MMA]/[EMA] ratio and catalyst type (Figure 4). With 1, using [MMA]/[EMA]/[EBiB]/[Al]/[Ru] $=200 / 100 / 2 / 4 / 1$, the conversion increased from $45 \%$ in $4 \mathrm{~h}$ to $60 \%$ after $16 \mathrm{~h}$; when the $[\mathrm{MMA}] /[\mathrm{EMA}]$ ratio was reversed to $100 / 200$, lower conversion was obtained in $4 \mathrm{~h}$, but it also reached $60 \%$ after $16 \mathrm{~h}$. With 2, using [MMA]/[EMA]/[EBiB]/[Al]/[Ru] $=200 / 100 / 2 / 4 / 1$, $35 \%$ of conversion was obtained in the beginning of the reaction, when reversing the [MMA]/[EMA] ratio to $100 / 200,25 \%$ of conversion was obtained in $4 \mathrm{~h}$. Initially, lower conversions were achieved at $[\mathrm{MMA}] /[\mathrm{EMA}]=100 / 200$ ratio for both catalysts. This can be explained by the lower reactivity of the EMA radical, considering that the pendant ethyl group provides greater stabilization of this monomeric radical. Similar conversion was obtained after $16 \mathrm{~h}$ regardless of $[\mathrm{MMA}] /[\mathrm{EMA}]$ ratio and catalyst type.

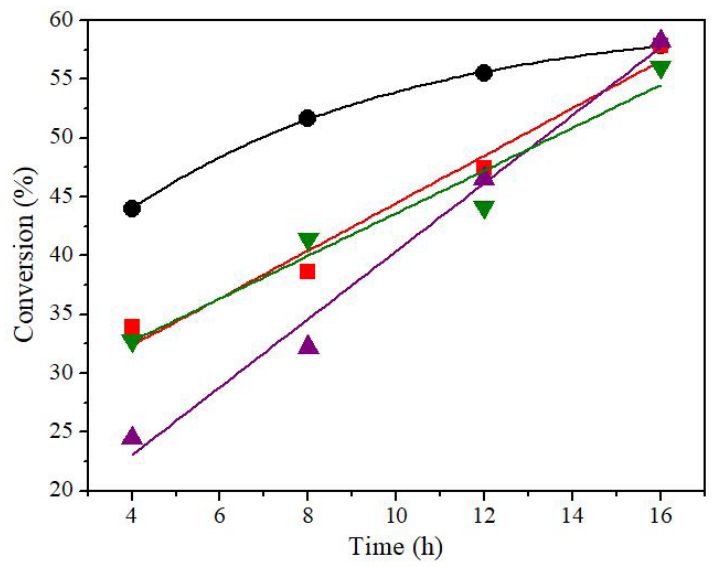

Figure 4. Dependence of conversion on the reaction time for copolymerization of MMA/EMA via ATRP using $\mathbf{1}$ or $\mathbf{2}$ from different starting [MMA]/[EMA] compositions in toluene at $85{ }^{\circ} \mathrm{C} ;[\mathrm{MMA}] /[\mathrm{EMA}] /[\mathrm{EB} i \mathrm{~B}] /[\mathrm{Al}] /[\mathbf{1}]=200 / 100 / 2 / 4 / 1$ $(\bullet),[\mathrm{MMA}] /[\mathrm{EMA}] /[\mathrm{EB} i \mathrm{~B}] /[\mathrm{Al}] /[\mathbf{1}]=100 / 200 / 2 / 4 / 1(\boldsymbol{\bullet})$, $[\mathrm{MMA}] /[\mathrm{EMA}] /[\mathrm{EB} i \mathrm{~B}] /[\mathrm{Al}] /[\mathbf{2}]=200 / 100 / 2 / 4 / 1(\boldsymbol{\nabla}),[\mathrm{MMA}] /$ $[\mathrm{EMA}] /[\mathrm{EBiB}] /[\mathrm{Al}] /[\mathbf{2}]=100 / 200 / 2 / 4 / 1(\mathbf{\Delta})$.
Detailed information on the molecular structure of poly(MMA-co-EMA) using $\mathbf{1}$ or $\mathbf{2}$ at both [MMA]/[EMA] ratios was obtained from the ${ }^{1} \mathrm{HNMR}$ spectra (Figure 5). In the ${ }^{1} \mathrm{H}$ NMR spectra of copolymers, signals at 3.59 and $4.04 \mathrm{ppm}$ are assigned to protons of the pendant methyl and ethyl group units, respectively. Signals between 0.87 and $1.03 \mathrm{ppm}$ are assigned to methyl protons of the MMA and EMA units. Therefore, the presence of MMA and EMA in the polymer backbones is evident, as copolymers are present and characterized by MMA/EMA dyad signals.

Table 1 shows the $F_{\mathrm{MMA}} / F_{\mathrm{EMA}}$ ratio, which corresponds to the relative amounts of MMA and EMA units in the isolated copolymer chains determined from the pendant methyl and ethyl group NMR signals. The amount of EMA in the copolymer increased using both $\mathbf{1}$ or $\mathbf{2}$ as the starting amount of EMA increased. Similar behavior was observed when the concurrent tandem catalysis for MMA/EMA copolymers was conducted by varying EtOH concentration (EMA source by in situ transesterification of MMA into EMA with EtOH in the presence of $\left.\mathrm{Al}(\mathrm{O} i \mathrm{Pr})_{3}\right)^{[29]}$. The dependences of glass transition temperatures $\left(T_{\mathrm{g}}\right)$ of poly(MMA)-co-(EMA) in the mixture composition are shown in Table 1. As expected, $T_{\mathrm{g}}$ decreases as the amount of EMA increases in the mixture using both catalysts. When comparing the $T_{\mathrm{g}}$ values obtained with G1 and G2, higher $T_{\mathrm{g}}$ values are observed for the poly(MMA)-co-(EMA) produced with $\mathrm{G} 1$ in both mixtures, corroborating the higher insertion of MMA units $\left(F_{\mathrm{MMA}} / F_{\mathrm{EMA}}\right)$ in the copolymer.

Copolymerization of MMA and EMA mediated by 1 showed living characteristics, as evidenced by the linear increase in molecular weight and decrease in polydispersity with conversion at both [MMA]/[EMA] ratios (Figure 6). $M_{n}$ values were at least one order of magnitude higher with $[$ MMA] $/[$ EMA] $=100 / 200$ compared with 200/100. When evaluating the relationship between theoretical and experimental molecular weights $\left(\mathrm{M}_{\mathrm{n}, \mathrm{exp}} / \mathrm{M}_{\mathrm{n} \text {,theor }}\right)$, the molecular weights closely agree with those predicted theoretically with $\mathrm{PDI}<1.5$ at $[\mathrm{MMA}] /[\mathrm{EMA}]=200 / 100$ using $\mathbf{1}$ as catalyst; in contrast, when the $[\mathrm{MMA}] /[\mathrm{EMA}]$ ratio is inverted to $100 / 200$, the molecular weights are higher than the theoretical values for both catalysts. This can be attributed to the number of growing
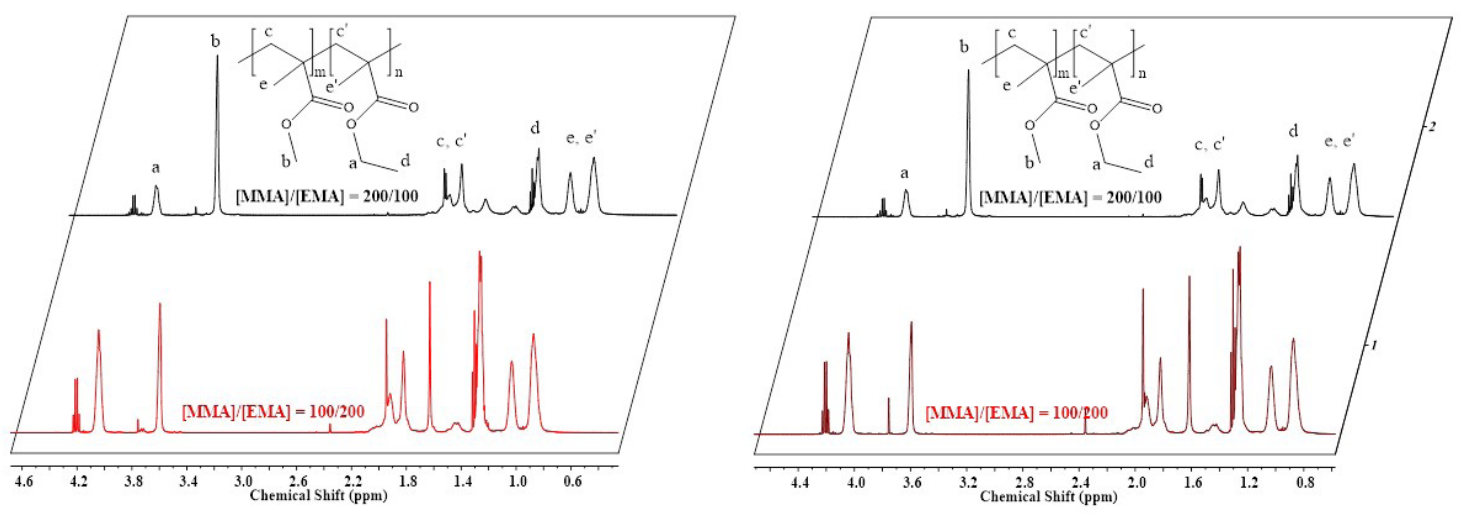

Figure 5. $1 \mathrm{H}$ NMR spectra of poly(MMA)-co-(EMA) obtained with 1 (above) and 2 (below) from different starting [MMA]/[EMA] compositions in toluene at $85^{\circ} \mathrm{C}$. 
Table 1. Copolymerization of MMA and EMA in the presence of $\mathrm{Al}(\mathrm{O} i \mathrm{Pr})_{3}{ }^{[a]}$ using 1 or 2 in toluene in $16 \mathrm{~h}$ at $85^{\circ} \mathrm{C}$.

\begin{tabular}{cccccccc}
\hline Catalyst & {$[\mathbf{M M A} /[\mathbf{E M A}]$} & $\begin{array}{c}\text { Conv. } .^{\text {[b] }} \\
\mathbf{( \% )}\end{array}$ & $\begin{array}{c}\mathbf{M}_{\mathbf{n}}^{\text {[c] }} \\
\left(\times \mathbf{1 0}^{\mathbf{3}}\right)\end{array}$ & $\begin{array}{c}\mathbf{M}_{\mathrm{n}, \text { theor }} \\
\left(\times \mathbf{1 0}^{\mathbf{3}}\right)\end{array}$ & $\mathbf{P D I}$ & $\begin{array}{c}\boldsymbol{F}_{\text {MMA }} / \boldsymbol{F}_{\text {EMA }} \\
(\mathbf{\%})^{[\mathrm{d}]}\end{array}$ & $\begin{array}{c}\boldsymbol{T}_{\boldsymbol{g}} \\
(\mathbf{K})\end{array}$ \\
\hline $\mathbf{1}$ & $200 / 100$ & 58 & 3.9 & 8.7 & 1.33 & $72 / 28$ & 343 \\
& $100 / 200$ & 58 & 12.6 & 8.7 & 1.64 & $43 / 57$ & 338 \\
$\mathbf{2}$ & $200 / 100$ & 56 & 26.2 & 8.4 & 1.89 & $69 / 31$ & 340 \\
& $100 / 200$ & 58 & 24.2 & 8.7 & 1.60 & $40 / 60$ & 332 \\
\hline
\end{tabular}

[a] $\left[\mathrm{Al}(\mathrm{Oi} \mathrm{Pr}] /[\mathrm{Ru}]=4\right.$ molar ratio; ${ }^{[\mathrm{b}]}$ Determined from the concentration of residual monomer measured by gas chromatography $(\mathrm{GC}) ;{ }^{[\mathrm{cc}]}$ Determined with size exclusion chromatography (SEC) with polystyrene calibration; ${ }^{[\mathrm{dd}}$ Calculated from ${ }^{1} \mathrm{H}$ NMR.

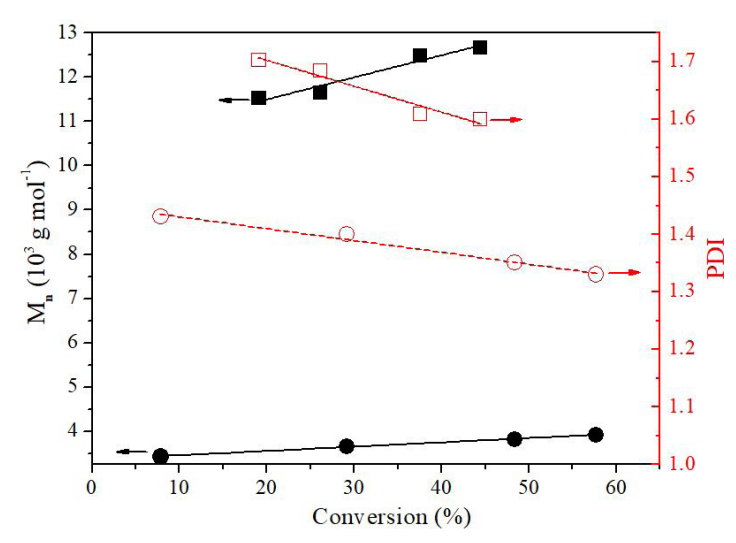

Figure 6. Dependence of $M_{n}$ (solid) and PDI (hollow) values on conversion for poly(MMA)-co-(EMA) obtained with 1 from different starting [MMA]/[EMA] compositions in toluene at $85^{\circ} \mathrm{C} ;[\mathrm{MMA}] /[\mathrm{EMA}] /[\mathrm{EB} i \mathrm{~B}] /[\mathrm{Al}] /[\mathbf{1}]=200 / 100 / 2 / 4 / 1(\bullet, \circ)$ and $[\mathrm{MMA}] /[\mathrm{EMA}] /[\mathrm{EB} i \mathrm{~B}] /[\mathrm{Al}] /[\mathbf{1}]=100 / 200 / 2 / 4 / 1(\boldsymbol{\bullet}, \square)$.

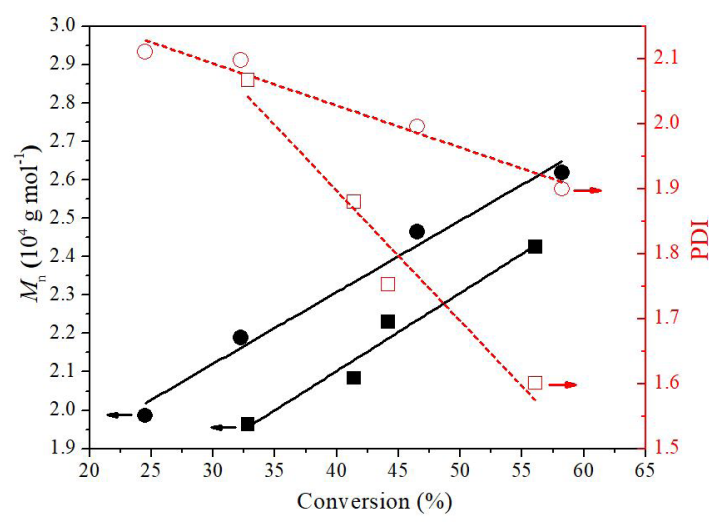

Figure 7. Dependence of Mn and PDI values on conversion for poly(MMA)-co-(EMA) obtained with 2 from different starting $[\mathrm{MMA}] /[\mathrm{EMA}]$ compositions in toluene at $85^{\circ} \mathrm{C}$; $[\mathrm{MMA}] /[\mathrm{EMA}] /[\mathrm{EBiB}] /[\mathrm{Al}] /[2]=200 / 100 / 2 / 4 / 1(\bullet, \circ)$ and $[\mathrm{MMA}] /[\mathrm{EMA}] /[\mathrm{EBiB}] /[\mathrm{Al}] /[2]=100 / 200 / 2 / 4 / 1(\mathbf{\bullet}$, 口).

radical chains being lower than expected, resulting in an effective increase in the monomer concentration. With $\mathbf{2}$, the molecular weight also increased linearly with conversion from $1.96 \times 10^{4}$ to $2.42 \times 10^{4} \mathrm{~g} \mathrm{~mol}^{-1}$ for $[\mathrm{MMA}] /[\mathrm{EMA}]=100 / 200$ and from $1.98 \times 10^{4}$ to $2.62 \times 10^{4} \mathrm{~g} \mathrm{~mol}^{-1}$ for $200 / 100$, but the molecular weights were systematically higher than expected with PDI values slightly higher (2.1-1.6) than those obtained with 1 (Figure 7). The bulkier properties of the $N$-heterocyclic ligand in $\mathbf{2}$, compared with the $\mathrm{PCy}_{3}$ ligand in $\mathbf{1}$, seem to hinder the reaction between catalyst and initiator or polymer-halide, adversely affecting the polymerization control. Therefore, when comparing the catalytic efficiency of $\mathbf{1}$ and $\mathbf{2}$ in the copolymerization of MMA and EMA, 1 provides greater control over polymerization in both [MMA]/[EMA] ratios evaluated. This greater catalytic efficiency for $\mathbf{1}$ may be associated with higher steric accessibility to the $\mathrm{Ru}$ center, considering that that the bulkier properties of the $\mathrm{N}$-heterocyclic in $\mathbf{2}$ seem to hinder the reaction between catalyst and initiator or polymer-halide.

\section{Conclusions}

Catalysts $\mathbf{1}$ or $\mathbf{2}$ were successfully applied for ATRP of EMA. Kinetics for the EMA polymerization demonstrated linear dependence on semilogarithmic coordinates and good agreement between of the experimental and theoretical molecular weights, and PDIs below 1.5. Most polymerizations occurred in a living fashion and were reasonably controlled with both catalysts. Poly(MMA)-co-(EMA) were synthesized in a reasonably controlled manner at different [MMA]/[EMA] ratios with both catalysts. The results show that control over polymerization and the polymerization yields are highly dependent on the catalyst. 1 was more efficient in controlling the polymerizations than $\mathbf{2}$, where the molecular weights increased in linear proportion with conversion and were closer to the calculated values, with narrower PDIs. Apparently, this greater catalytic efficiency for $\mathbf{1}$ may be associated with higher steric accessibility to the $\mathrm{Ru}$ center, considering that that the bulkier properties of the $\mathrm{N}$-heterocyclic in $\mathbf{2}$ seem to hinder the reaction between catalyst and initiator or polymer-halide.

\section{Acknowledgements}

The authors are indebted to the financial support from FAPESP (Proc. 2013/10002-0) and Prope (Proc. 2180/002/14-PROPe/CDC). The $400 \mathrm{MHz}-\mathrm{NMR}$ analyses were performed at the Instituto de Química de São Carlos - IQSC/USP, São Carlos, SP, Brazil.

\section{References}

1. Kato, M., Kamigaito, M., Sawamoto, M., \& Higashimura, T. (1995). Polymerization of methyl methacrylate with the carbon tetrachloride/dichlorotris- (triphenylphosphine)ruthenium(II)/ methylaluminum Bis(2,6-di-tert-butylphenoxide) initiating system: possibility of living radical polymerization. Macromolecules, 28(5), 1721-1723. http://dx.doi.org/10.1021/ma00109a056. 
2. Wang, J. S., \& Matyjaszewski, K. (1995). Controlled/'living" radical polymerization: atom transfer radical polymerization in the presence of transition-metal complexes. Journal of the American Chemical Society, 117(20), 5614-5615. http://dx.doi. org/10.1021/ja00125a035.

3. Wang, J. S., \& Matyjaszewski, K. (1995). Controlled/'living" radical polymerization: halogen atom transfer radical polymerization promoted by a $\mathrm{Cu}(\mathrm{I}) / \mathrm{Cu}(\mathrm{II})$ redox process. Macromolecules, 28(23), 7901-7910. http://dx.doi.org/10.1021/ma00127a042.

4. Matyjaszewski, K., \& Tsarevsky, N. V. (2009). Nanostructured functional materials prepared by atom transfer radical polymerization. Nature Chemistry, 1(4), 276-288. http://dx.doi. org/10.1038/nchem.257. PMid:21378870.

5. Di Lena, F., \& Matyjaszewski, K. (2010). Transition metal catalysts for controlled radical polymerization. Progress in Polymer Science, 35(8), 959-1021. http://dx.doi.org/10.1016/j. progpolymsci.2010.05.001.

6. Lee, H., Pietrasik, J., Sheiko, S. S., \& Matyjaszewski, K. (2010). Stimuli-responsive molecular brushes. Progress in Polymer Science, 35(1-2), 24-44. http://dx.doi.org/10.1016/j. progpolymsci.2009.11.002.

7. Siegwart, D. J., Oh, J. K., \& Matyjaszewski, K. (2012). ATRP in the design of functional materials for biomedical applications. Progress in Polymer Science, 37(1), 18-37. http://dx.doi org/10.1016/j.progpolymsci.2011.08.001. PMid:23525884.

8. Matyjaszewski, K. (2012). Atom Transfer Radical Polymerization (ATRP): current status and future perspectives. Macromolecules, 45(10), 4015-4039. http://dx.doi.org/10.1021/ma3001719.

9. Wever, D. A. Z., Raffa, P., Picchioni, F., \& Broekhuis, A. A. (2012). Acrylamide homopolymers and Acrylamide-Nisopropylacrylamide block copolymers by atomic transfer radical polymerization in water. Macromolecules, 45(10), 4040-4045. http://dx.doi.org/10.1021/ma3006125.

10. Matyjaszewski, K., \& Tsarevsky, N. V. (2014). Macromolecular engineering by atom transfer radical polymerization. Journal of the American Chemical Society, 136(18), 6513-6533. http:// dx.doi.org/10.1021/ja408069v. PMid:24758377.

11. Chmielarz, P., Park, S., Simakova, A., \& Matyjaszewski, K. (2015). Electrochemically mediated ATRP of acrylamides in water. Polymer, 60(9), 302-307. http://dx.doi.org/10.1016/j. polymer.2015.01.051.

12. Wu, W., Wang, W., \& Li, J. (2015). Star polymers: advances in biomedical applications. Progress in Polymer Science, 46, 55-85. http://dx.doi.org/10.1016/j.progpolymsci.2015.02.002.

13. Matyjaszewski, K., \& Davis, T. (2002). Handbook of radical polymerization. Hoboken: Wiley-Interscience. http://dx.doi. org/10.1002/0471220450.

14. Kamigaito, M., Ando, T., \& Sawamoto, M. (2004). Metal-catalyzed living radical polymerization: discovery and developments. Chemical Record, 4(3), 159-175. http://dx.doi.org/10.1002/ tcr.20011. PMid:15293337.

15. Matyjaszewski, K. (1999). Transition metal catalysis in controlled radical polymerization: atom transfer radical polymerization. Chemistry, 5(11), 3095-3102. http://dx.doi.org/10.1002/(SICI)15213765(19991105)5:11<3095::AID-CHEM3095>3.0.CO;2-\#.

16. Matyjaszewski, K., \& Xia, J. (2001). Atom transfer radical polymerization. Chemical Reviews, 101(9), 2921-2990. http:/ dx.doi.org/10.1021/cr940534g. PMid:11749397.

17. Kamigaito, M., Ando, T., \& Sawamoto, M. (2001). Metalcatalyzed living radical polymerization. Chemical Reviews, 101(12), 3689-3746. http://dx.doi.org/10.1021/cr9901182. PMid:11740919.

18. Dragutan, V., \& Dragutan, I. (2006). A resourceful new strategy in organic synthesis: tandem and stepwise metathesis/nonmetathesis catalytic processes. Journal of Organometallic Chemistry, 691(24-25), 5129-5147. http://dx.doi.org/10.1016/j. jorganchem.2006.08.012.

19. Simal, F., Demonceau, A., \& Noels, A. F. (1999). Highly efficient ruthenium-based catalytic systems for the controlled free-radical polymerization of vinyl monomers. Angewandte Chemie International Edition, 38(4), 538-540. http://dx.doi. org/10.1002/(SICI)1521-3773(19990215)38:4<538::AIDANIE538>3.0.CO;2-W

20. Lee, J., Grandner, J. M., Engle, K. M., Houk, K. N., \& Grubbs, R. H. (2016). In situ catalyst modification in atom transfer radical reactions with ruthenium benzylidene complexes. Journal of the American Chemical Society, 138(22), 7171-7177. http:// dx.doi.org/10.1021/jacs.6b03767. PMid:27186790.

21. Afonso, M. B. A., Gonçalves, L. G., Borim, P., Sá, J. L. S., Goi, B. E., \& Carvalho-Júnior, V. P., (2007). Atom transfer radical polymerization of methyl methacrylate mediated by Grubbs 1st and 2nd generation catalysts: insight into the active species. Journal of the Brazilian Chemical Society, 28(8), 1407-1413. http://dx.doi.org/10.21577/0103-5053.20160314

22. Kitayama, T., Ute, K., Yamamoto, M., Fujimoto, N., \& Hatada, K. (1990). Highly isotactic and living polymerization of ethyl methacrylate with $t-\mathrm{C}_{4} \mathrm{H}_{9} \mathrm{MgBr}$ in toluene and the preparation of block and random copolymers with high stereoregularity. Polymer Journal, 22(5), 386-396. http://dx.doi.org/10.1295/ polymj.22.386.

23. Kitayama, T., Nakagawa, O., \& Hatada, K. (1995). Stereospecific polymerization of stereoregular poly(methyl methacrylate) macromonomer and determination of main-chain tacticity of resulting polymacromonomer. Polymer Journal, 28(2), 150-154. http://dx.doi.org/10.1295/polymj.28.150.

24. Zune, C., Zundel, T., Dubois, P., Teyssié, P., \& Jerômé, R. (1999). New initiator system for the anionic polymerization of (meth)acrylates in toluene. IV. Random copolymerization of (meth)acrylates in toluene initiated by s-BuLi ligated by lithium silanolates. Journal of Polymer Science. Part A, Polymer Chemistry, 37(14), 2525-2535. http://dx.doi.org/10.1002/(SICI)10990518(19990715)37:14<2525::AID-POLA26>3.0.CO;2-M.

25. Dzulkurnain, N. A., Hanifah, S. A., Ahmad, A., \& Mohamed, N. S. (2015). Characterization of random methacrylate copolymers synthesized using free-radical bulk polymerization method. International Journal of Electrochemical Science, 10(1), 8492. Retrieved in 2017, July 10, from https://ukm.pure.elsevier. com/en/publications/characterization-of-random-methacrylatecopolymers-synthesized-us

26. Shin, B. S., \& Seul, S. D. (1993). Solution copolymerization of methyl methacrylate and alkyl methacrylates in a continuous stirred tank reactor(CSTR). Korean Journal of Chemical Engineering, 10(1), 1-9. http://dx.doi.org/10.1007/BF02697371.

27. Liu, G., Zhang, L., Wang, Y., \& Zhao, P. (2009). Studies on binary copolymerization and glass transition temperatures of methyl methacrylate with ethyl methacrylate and $n$-butyl methacrylate. Journal of Applied Polymer Science, 114(6), 3939-3944. http:// dx.doi.org/10.1002/app.30961.

28. Giles, M. R., Hay, J. N., \& Howdle, S. M. (2000). The copolymerisation of methyl and ethyl methacrylate in supercritical carbon dioxide. Macromolecular Rapid Communications, 21(15), 1019-1023. http://dx.doi.org/10.1002/1521-3927(20001001)21:15<1019::AIDMARC1019>3.0.CO;2-M.

29. Nakatani, K., Ogura, Y., Koda, Y., Terashima, T., \& Sawamoto, M. (2012). Sequence-regulated copolymers via tandem catalysis of living radical polymerization and in situ transesterification. Journal of the American Chemical Society, 134(9), 4373-4383. http://dx.doi.org/10.1021/ja211436n. PMid:22296320.

Received: July 10, 2017

Revised: Aug. 16, 2017 Accepted: Aug. 17, 2017 